\title{
Occurrence and genotyping of Giardia duodenalis and Cryptosporidium in pre-weaned dairy calves in central Sichuan province, China
}

\author{
Zhijun Zhong ${ }^{1, a,{ }^{*}}$, Jiaming Dan ${ }^{1, a}$, Guangwen Yan $^{2, a}$, Rui Tu${ }^{1}$, Yinan Tian ${ }^{1}$, Suizhong Cao ${ }^{1}$, Liuhong Shen ${ }^{1}$, \\ Junliang Deng ${ }^{1}$, Shumin $\mathrm{Yu}^{1}$, Yi Geng ${ }^{1}$, Xiaobin $\mathrm{Gu}^{1}$, Ya Wang ${ }^{1}$, Haifeng Liu ${ }^{1}$, and Guangneng Peng ${ }^{1, *}$ \\ ${ }^{1}$ Key Laboratory of Animal Disease and Human Health of Sichuan Province, College of Veterinary Medicine, Sichuan Agricultural \\ University, Sichuan 611130, PR China \\ ${ }^{2}$ College of Animal Science, Xichang University, Xichang 615000, PR China
}

Received 6 February 2018, Accepted 3 August 2018, Published online 4 September 2018

\begin{abstract}
Giardia duodenalis and Cryptosporidium spp. are common human and animal pathogens. They have increasingly been reported in dairy calves in recent years; however, multilocus genotyping information for G. duodenalis and Cryptosporidium infecting pre-weaned dairy calves in southwestern China is limited. In the present study, the prevalence of $G$. duodenalis and Cryptosporidium spp. in pre-weaned dairy calves in central Sichuan province was determined and the pathogens were analyzed molecularly. Of 278 fecal samples from pre-weaned dairy calves, $26(9.4 \%)$ were positive for $G$. duodenalis and $40(14.4 \%)$ were positive for Cryptosporidium spp. Cryptosporidium bovis $(n=28)$, Cryptosporidium ryanae $(n=5)$ and Cryptosporidium parvum $(n=7)$ were detected. All seven C. parvum isolates were successfully subtyped based on the gp60 gene sequence, and only IIdA15G1 was detected. Multilocus sequence typing of $G$. duodenalis based on beta-giardin ( $b g$ ), triose phosphate isomerase (tpi) and glutamate dehydrogenase $(g d h)$ genes revealed 19 different assemblage E multilocus genotypes (two known and 17 unpublished genotypes). Based on eBURST analysis, a high degree of genetic diversity within assemblage E was observed in pre-weaned dairy calves in Sichuan province. To the best of our knowledge, this is the first study using multilocus sequence typing and eBURST analysis to characterize $G$. duodenalis in pre-weaned dairy calves in southwestern China.
\end{abstract}

Key words: Giardia duodenalis, Cryptosporidium, Multilocus genotyping, Pre-weaned dairy calves, Sichuan province.

Résumé - Présence et génotypage de Giardia duodenalis et Cryptosporidium chez des veaux laitiers pré-sevrés dans la province centrale du Sichuan, Chine. Giardia duodenalis et Cryptosporidium spp. sont des pathogènes humains et animaux communs. Ils ont été signalés de plus en plus chez les veaux laitiers au cours des dernières années; cependant, l'information de génotypage multilocus pour G. duodenalis et Cryptosporidium infectant les veaux laitiers pré-sevrés dans le sud-ouest de la Chine est limitée. Dans la présente étude, la prévalence de G. duodenalis et de Cryptosporidium spp. chez les veaux laitiers pré-sevrés dans la province centrale du Sichuan a été déterminée et les pathogènes ont été analysés moléculairement. Dans 278 échantillons fécaux de veaux laitiers pré-sevrés, 26 (9.4\%) étaient positifs pour $G$. duodenalis et 40 (14.4\%) étaient positifs pour Cryptosporidium spp. Cryptosporidium bovis $(n=28)$, Cryptosporidium ryanae $(n=5)$ et Cryptosporidium parvum $(n=7)$ ont été détectés. Les sept isolats de $C$. parvum ont été sous-typés avec succès sur la base de la séquence du gène gp60 et seul IIdA15G1 a été détecté. Le typage multilocus de G. duodenalis basé sur les gènes de béta-giardine (bg), triose phosphate isomérase (tpi) et glutamate déshydrogénase ( $\mathrm{gdh}$ ) a révélé 19 génotypes différents d'assemblage multilocus E (deux génotypes connus et 17 non-publiés). D'après l'analyse eBURST, on a observé un degré élevé de diversité génétique au sein de l'assemblage E chez les veaux laitiers pré-sevrés de la province du Sichuan. À notre connaissance, il s'agit de la première étude utilisant le typage de séquence multilocus et l'analyse eBURST pour caractériser $G$. duodenalis chez des veaux laitiers pré-sevrés dans le sud-ouest de la Chine.

\footnotetext{
*Corresponding authors. zhongzhijun488@126.com; pgn.sicau@163.com
}

${ }^{\text {a }}$ These authors contributed equally to this work.

This is an Open Access article distributed under the terms of the Creative Commons Attribution License (http://creativecommons.org/licenses/by/4.0), which permits unrestricted use, distribution, and reproduction in any medium, provided the original work is properly cited. 


\section{Introduction}

Protists of the genera Giardia and Cryptosporidium infect a wide range of animals as well as humans [3, 12, 19]. Typically, the infection is acquired following the ingestion of highly resilient, infective stages (oocysts or cysts) via the fecal-oral route $[3,4]$. Disease is commonly associated with clinical signs including diarrhea, dehydration, fever, inappetence and anorexia. Infections are often self-limiting in immune-competent individuals $[2,31]$, but can be chronic and severe in infants, elderly people, and immune-compromised individuals $[9,16]$.

Ruminants are recognized as a significant reservoir of Giardia and Cryptosporidium taxa that infect animals and humans $[19,21]$. Current data indicate that of the eight assemblages within Giardia duodenalis, assemblages A and E and the Cryptosporidium species C. parvum, C. andersoni, C. ryanae, and $C$. bovis predominate in cattle worldwide $[4,20]$.

Unlike in other countries (e.g. Australia, Sudan, Japan and India) $[6,14,15,24]$, where $C$. parvum is known to be the predominant species in pre-weaned calves, this does not appear to be the case everywhere in China. Some studies have shown that C. parvum is a major species in pre-weaned calves in some regions, whereas $C$. bovis is a major species in other regions $[5,25,28]$.

According to the National Bureau of Statistics of the People's Republic of China, in 2016, the total population of dairy cattle in Sichuan Province was 176 thousand heads. However, no information about $G$. duodenalis and Cryptosporidium infection of pre-weaned dairy calves was previously available in Sichuan Province. We undertook a molecular epidemiological study to obtain a preliminary snap-shot of the prevalence of G. duodenalis assemblages and Cryptosporidium genotypes in pre-weaned calves in Sichuan province, China.

\section{Materials and methods \\ Sample collection}

We collected 278 rectal fecal samples from pre-weaned dairy calves $(<1$ month of age) from 10 farms with a history of bovine diarrhea in 10 regions in Sichuan province, southwestern China, between June 2016 and March 2017. Collection sites included: Chengdu $\left(104^{\circ} 06^{\prime} \mathrm{E}, 30^{\circ} 57^{\prime} \mathrm{N}\right)$, Hongya $\left(103^{\circ} 37^{\prime} \mathrm{E}, 29^{\circ} 91^{\prime} \mathrm{N}\right), \mathrm{Aba}\left(102^{\circ} 22^{\prime} \mathrm{E}, 31^{\circ} 90^{\prime} \mathrm{N}\right)$, Meishan $\left(103^{\circ} 84^{\prime} \mathrm{E}, 30^{\circ} 08^{\prime} \mathrm{N}\right)$, Mianyang $\left(104^{\circ} 67^{\prime} \mathrm{E}, 31^{\circ} 47^{\prime} \mathrm{N}\right)$, Ziyang $\left(104^{\circ} 62^{\prime} \mathrm{E}, 30^{\circ} 13^{\prime} \mathrm{N}\right)$, Anyue $\left(105^{\circ} 33^{\prime} \mathrm{E}, 30^{\circ} 10^{\prime} \mathrm{N}\right)$, Qionglai $\left(103^{\circ} 46^{\prime} \mathrm{E}, 30^{\circ} 41^{\prime} \mathrm{N}\right)$, Qingbaijiang $\left(104^{\circ} 25^{\prime} \mathrm{E}, 30^{\circ} 88^{\prime} \mathrm{N}\right)$, and Deyang $\left(104^{\circ} 39^{\prime} \mathrm{E}, 31^{\circ} 13^{\prime} \mathrm{N}\right)$. The 10 farms are distributed in central Sichuan Province (Fig. 1). The city-level map was provided by the National Geomatics Centre of China (National Geomatics Centre of China, Beijing, China, http://ngcc.sbsm. gov.cn/).

Of the 10 farms, six (Chengdu, Hongya, Aba, Mianyang, Ziyang, and Qionglai) are intensive feeding farms, while the other four are free-ranging. For intensive farms, there were approximately $1000-2500$ cattle per farm, with more than 100 pre-weaned dairy calves, and the fecal samples were randomly collected from about $20 \%$ in each farm. For freeranging farms, there were approximately $100-120$ cattle per farm and the herd sizes of pre-weaned dairy calves were less than 50; in this case we collected fecal samples from all of the pre-weaned dairy calves at each farm (Table S1). In intensive farms, calves were bred in different calf stalls, with one hour outdoor time after eating and excretion in the morning and afternoon, respectively. Calves shared one yard during the outdoor time in intensive farms. In free-ranging farms, calves were kept in a field with a half cover and were raised together. The farms we selected had solely cattle, and no other animals.

Fecal samples were collected from the rectum using disposable gloves, transferred into disposable plastic bags, and stored in $2.5 \%$ potassium dichromate at $4{ }^{\circ} \mathrm{C}$.

\section{DNA extraction}

Before DNA extraction, feces were washed with distilled water to remove potassium dichromate. Genomic DNA was extracted from $250 \mathrm{mg}$ (approximately) of individual samples using the Power Soil DNA isolation kit (MOBIO, USA), according to the manufacturer's instructions, and frozen at $-20{ }^{\circ} \mathrm{C}$ until use.

\section{PCR amplification and sequencing}

G. duodenalis was detected by nested PCR amplification of the $b g g$ ene. The $b g$-positive samples were further characterized by amplifications of $g d h$ and tpi. Genotyping of Cryptosporidium was based on amplification of the small subunit (SSU) rRNA gene by nested PCR and subsequent sequence analysis. All the C. parvum isolates were further characterized by amplification of the gp 60 gene. The primers and amplification conditions in this study were described previously $[1,11,23]$. Positive and negative controls were included in each test. The secondary PCR products were visualized under UV light after electrophoresis on a $1 \%$ agarose gel mixed with Golden View.

All positive secondary PCR products were sent to Invitrogen (Shanghai, China) and sequenced in both directions. Sequences were aligned with reference sequences from GenBank using BLAST (http://blast.ncbi.nlm.nih.gov) and ClustalX.

A previous nomenclature system was used to name subtypes at each genetic locus $[29,30]$. Specimens that were successfully subtyped at all three loci were included in multilocus genotyping of $G$. duodenalis. The genetic pedigree of the assemblage E multilocus genotypes (MLGs) was assessed by using eBURST 3.0 (http://eBURST.mlst.net).

\section{Statistical analysis}

The $\chi^{2}$ test was used to compare the infection rates of G. duodenalis and Cryptosporidium in different feeding patterns. Differences were considered significant at $p<0.05$.

\section{Results and discussion}

G. duodenalis was detected in $9.4 \%$ of 278 pre-weaned dairy calves on 6 of 10 farms, with prevalences ranging from $7.7 \%$ to $46.4 \%$ (Table 1). Its prevalence shows substantial 


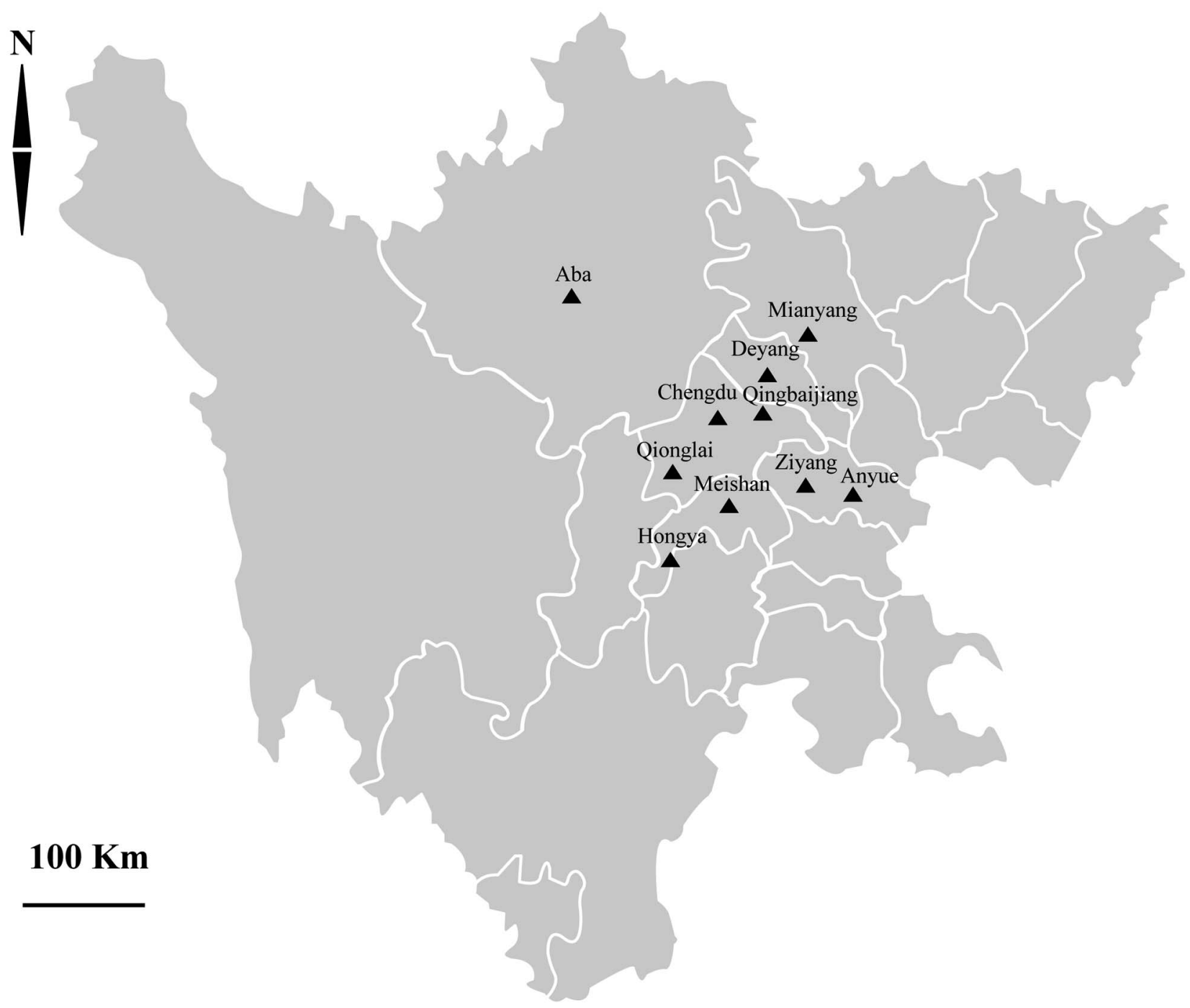

Figure 1. Distribution of sampling sites in Sichuan province in this study.

Table 1. Prevalence of Cryptosporidium and G. duodenalis in pre-weaned diary calves in Sichuan province.

\begin{tabular}{|c|c|c|c|c|c|c|c|}
\hline \multirow[b]{2}{*}{ Region } & \multirow[b]{2}{*}{ No. tested } & \multicolumn{3}{|c|}{ Cryptosporidium } & \multirow{2}{*}{$\begin{array}{l}\text { Cryptosporidium No. (\%) } \\
\text { of positive specimens }\end{array}$} & \multirow[b]{2}{*}{ G. duodenalis } & \multirow{2}{*}{$\begin{array}{l}\text { G. duodenalis } \\
\text { infection rate }\end{array}$} \\
\hline & & C. bovis & C. ryanae & C. parvum & & & \\
\hline$\overline{\text { Chengdu }^{\mathrm{a}}}$ & 39 & 2 & 1 & & $3(7.7 \%)$ & 3 & $7.7 \%$ \\
\hline Hongya $^{a}$ & 24 & 1 & & & $1(4.2 \%)$ & & \\
\hline $\mathrm{Aba}^{\mathrm{a}}$ & 20 & & & 7 & $7(35.0 \%)$ & 2 & $10.0 \%$ \\
\hline Meishan ${ }^{\mathrm{b}}$ & 20 & & & & & & \\
\hline Mianyang & 58 & 8 & 3 & & $11(19.0 \%)$ & & \\
\hline Ziyang $^{\mathrm{a}}$ & 26 & 8 & & & $8(30.8 \%)$ & 2 & $7.7 \%$ \\
\hline Anyue ${ }^{b}$ & 22 & 2 & & & $2(9.1 \%)$ & 3 & $13.6 \%$ \\
\hline Qionglai $^{\mathrm{a}}$ & 28 & 4 & & & $4(14.3 \%)$ & 13 & $46.4 \%$ \\
\hline Qingbaijiang $^{\mathrm{b}}$ & 20 & 2 & & & $2(10.0 \%)$ & 3 & $15.0 \%$ \\
\hline Deyang ${ }^{\mathrm{b}}$ & 21 & 1 & 1 & & $2(9.5 \%)$ & & \\
\hline Total & 278 & 28 & 5 & 7 & $40(14.4 \%)$ & 26 & $9.4 \%$ \\
\hline
\end{tabular}

\footnotetext{
a Intensive farming;
}

${ }^{\mathrm{b}}$ free-ranging. 
Table 2. Multilocus sequence genotypes of G. duodenalis in pre-weaned dairy calves in Sichuan province.

\begin{tabular}{|c|c|c|c|c|c|}
\hline \multirow[t]{2}{*}{ Isolate } & \multirow[t]{2}{*}{ Geographic source } & \multicolumn{3}{|c|}{ Subtype } & \multirow[t]{2}{*}{ MLG } \\
\hline & & $b g$ & tpi & $g d h$ & \\
\hline ABG3417 & $A^{\prime} b a$ & E9 & E15 & \#E19/MF671896 & $\overline{\text { \#MLGE72 }}$ \\
\hline ABG3422 & & E1 & E15 & \#E19/MF671896 & \#MLG E74 \\
\hline AYG6943 & Anyue & \#E13/MF671880 & E1 & E10 & \#MLG E70 \\
\hline AYG6950 & & \#E14/MF671883 & E3 & E10 & \#MLG E67 \\
\hline AYG6953 & & E1 & E3 & E3 & \#MLG E62 \\
\hline CDG16089 & Chengdu & E9 & E3 & E1 & \#MLG E61 \\
\hline CDG16090 & & E8 & E9 & E10 & \#MLG E60 \\
\hline CDG16100 & & E9 & E19 & E1 & \#MLG E68 \\
\hline QBJG13 & Qingbaijiang & \#E14/MF671883 & E3 & E10 & \#MLG E67 \\
\hline QBJG17 & & \#E16/MF671886 & E3 & E3 & \#MLG E63 \\
\hline QBJG18 & & E9 & E3 & E10 & MLG E3 \\
\hline QLG5065 & Qionglai & E1 & \#E24/MF671907 & \#E19/MF671896 & \#MLG E75 \\
\hline QLG5066 & & E9 & E3 & E10 & MLG E3 \\
\hline QLG5067 & & E1 & E3 & E8 & \#MLG E64 \\
\hline QLG5070 & & E1 & E15 & E1 & \#MLG E65 \\
\hline QLG5071 & & E9 & E1 & \#E19/MF671896 & \#MLG E73 \\
\hline QLG5073 & & E1 & & E10 & \\
\hline QLG5074 & & E1 & E15 & E1 & \#MLG E65 \\
\hline QLG5075 & & \#E13/MF671880 & E3 & E1 & MLG E13 \\
\hline QLG5076 & & \#E13/MF671880 & E3 & \#E20/MF671899 & \#MLG E59 \\
\hline QLG5083 & & E1 & E3 & $\mathrm{E} 1$ & \#MLG E66 \\
\hline QLG5091 & & \#E13/MF671880 & E3 & E1 & MLG E13 \\
\hline QLG5092 & & \#E13/MF671880 & E3 & E1 & MLG E13 \\
\hline QLG5093 & & \#E13 & & & \\
\hline ZYG6863 & Ziyang & E9 & E1 & E1 & \#MLGE71 \\
\hline ZYG6844 & & E15 & \#E21/MF671904 & E13 & \#MLG E69 \\
\hline
\end{tabular}

\# Unpublished subtypes and MLGs.

differences, ranging from $7.1 \%$ to $60.1 \%$ in other studies in China [7, 13, 18, 26, 29]. In this study, the overall infection rate in southwestern China was close to the prevalence in northwestern (9.7\% [18]), northeastern (13.3\% [13]) and north China (7.1\% [7]), but much lower than the infection rates in central (17.6\% [26]) and southeastern (60.1\% [29]) China. Prior to the present study, these results were interpreted as related to differences in geographic distribution, environmental management and cultivation scale [7, 13, 18, 26, 29]. Cattle were kept in groups or in free stalls, which might promote the transmission of $G$. duodenalis infection among animals and lead to the high infection rates [26, 29]. Furthermore, we analyzed the infection rates between intensive feeding and free-ranging farms; there was no significant difference between the two breeding patterns $\left(X^{2}=0.629, d f=1, p=0.428\right)$.

Cryptosporidium was detected in $14.4 \%$ of 278 fecal samples, on 9 out of 10 farms, with prevalences ranging from $4.2 \%$ to $35.0 \%$ (Table 1). The overall infection rate for Cryptosporidium is lower than the average prevalence of $19.5 \%$ reported previously in pre-weaned cattle in China [5], but similar to the infection rate reported in Xinjiang (15.6\%) [17], and much higher than the rate in Hebei and Tianjin, China (1.0\%) [7]. Prevalence of Cryptosporidium was significantly different $\left(X^{2}=4.924, d f=1, p=0.026\right)$ between intensive feeding and free-ranging farms in this study, which suggests that cultivation scale may lead to differences in infection rates with Cryptosporidium. Other studies also showed that geographic distribution and host health status may lead to the difference
[5, 10, 17]. Three species of Cryptosporidium (28 C. bovis, 7 C. parvum [subtype IIdA15G1] and 5 C. ryanae) were identified in this study. Previous studies have shown that $C$. parvum is a major species in pre-weaned calves in Beijing [10], Xinjiang [17] and Ningxia [8], whereas C. bovis predominated in pre-weaned calves in this study, similar to reports from Henan [27] and Heilongjiang [32].

Giardia duodenalis in all 26 positive samples corresponded to assemblage E. G. duodenalis infection is relatively common in pre-weaned dairy calves. We further characterized the 26 $G$. duodenalis bg-positive samples at the tpi and gdh loci. Among these 26 samples, the tpi and $g d h$ loci were successfully amplified and sequenced in 24 and 25 specimens, respectively. The $b g$, tpi and $g d h$ loci all showed high levels of sequence polymorphism; seven subtypes were identified at each locus. Of the $b g$ subtypes, E1 (MF671885), E8 (KY769093), E9 (KY769091), and E15 (KT698677) were known, and E13 (MF671880), E14 (MF671883), and E16 (MF671886) were unpublished. At the tpi locus, five known subtypes E1 (MF671900), E3 (KT922259), E9 (EF654690), E15 (KY432848) and E19 (KY769103) and two unpublished subtypes, E21 (MF671904) and E24 (MF671907), were found. The sequences from the $g d h$ locus represented five known subtypes E1 (MF671891), E3 (KT369780), E8 (KT368785), E10 (KT698971), E13 (KY432838) and two unpublished subtypes, E19 (MF671896) and E20 (MF671899).

For $G$. duodenalis, multi-locus genotyping analysis suggested a high genetic diversity of assemblage $\mathrm{E}$ in pre-weaned 


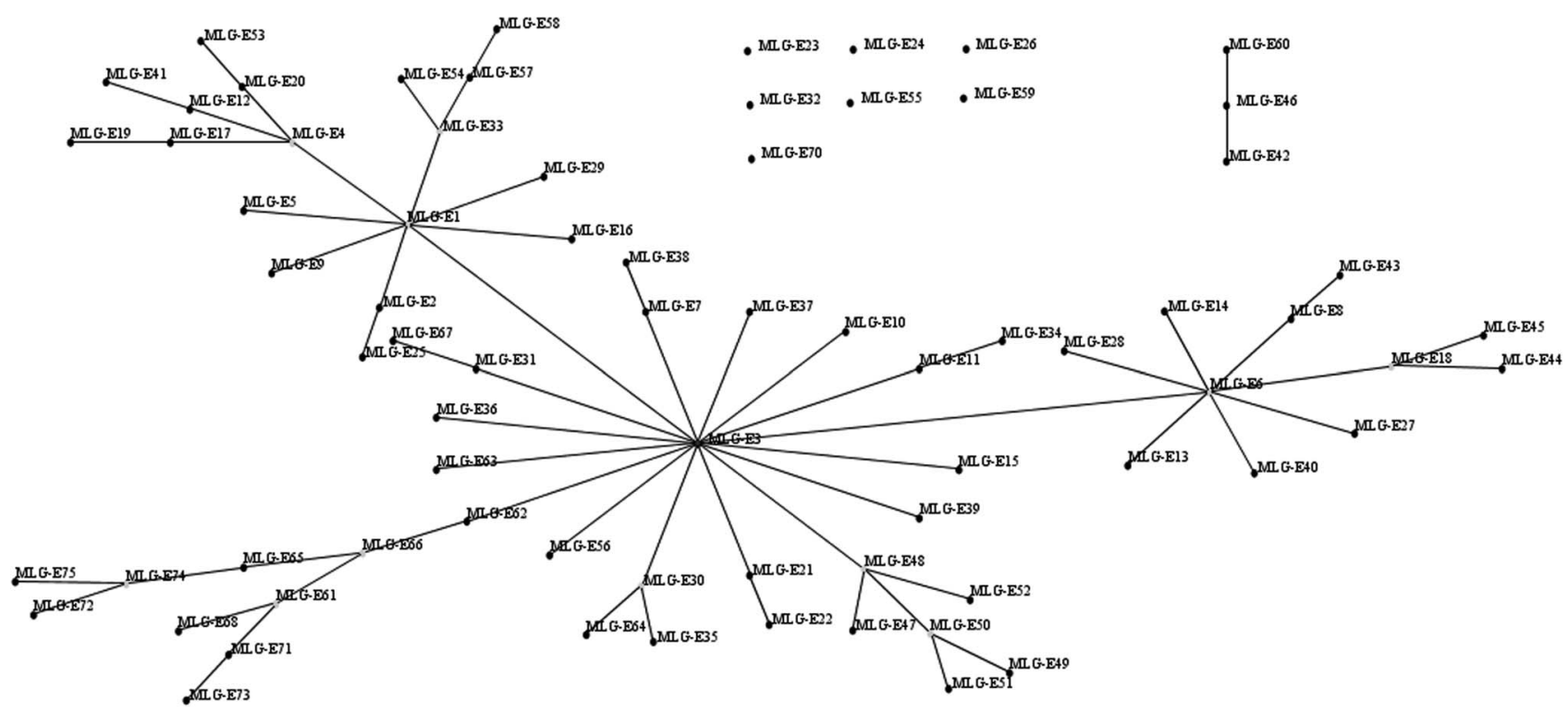

Figure 2. eBURST networks for G. duodenalis assemblage E. Each MLG is represented by a dot. MLG-E3 is the primary founder, and the subgroup founders are MLG-E1, MLG-E4, MLG-E33, MLG-E66, MLG-E61, MLG-E74, MLG-E30, MLG-E48, MLG-E50, MLG-E6, and MLG-E18. The variants are connected by lines.

dairy calves in this study. Based on the combination of $b g$, tpi and $g d h$ loci, 19 MLGs of assemblage E were detected (Table 2). A high degree of nucleotide variation in assemblage $\mathrm{E}$ has been also detected in previous studies [18, 22, 26, 29]. Of the 19 MLGs, 17 were unpublished MLGs. The majority of MLGs were MLG-E3 and MLG-E13, which have also been detected in dairy calves in Shanghai [29]. To further analyze the evolutionary descent of the 19 assemblage E MLGs, we used eBURST analysis of the 19 assemblage E MLGs and 58 reference MLGs, which revealed two clonal complexes and seven singletons (Fig. 2). MLG-E3 is the primary founder of clonal complex 1, which is consistent with findings in a previous study in Shanghai [29]. The majority of MLGs (14/19) originated from MLG-E3. Furthermore, MLG-E60 is a variant of clonal complex 2, and MLG-E59 and MLG-E70 were singletons. The latter three MLG subtypes showed distant evolution from other assemblage E MLGs, which may indicate substantial differences in their evolutionary divergence [29].

\section{Conclusion}

This is the first study to genotype $G$. duodenalis and Cryptosporidium in pre-weaned dairy calves in Sichuan province. C. bovis and G. duodenalis assemblage $\mathrm{E}$ are the dominant species in pre-weaned dairy calves in Sichuan, and high genetic diversity of assemblage E MLGs was observed.

\section{Statements}

\section{Ethics approval and consent to participate}

This study was reviewed and approved by the Institutional Animal Care and Use Committee of Sichuan Agricultural University under permit number DYY-S20174604.

\section{Consent for publication}

Not applicable.

\section{Availability of data and material}

The datasets supporting the conclusions of this article are included within the article. Cryptosporidium and G. duodenalis sequences were deposited in the GenBank database under accession numbers MF671870-MF671908.

\section{Competing interests}

The authors declare that they have no conflict of interest.

\section{Funding}

This work was supported by the National Key Research and Development Program of China (2016YFD0501009); the National Natural Science Foundation of China (31272620); and the Chengdu Giant Panda Breeding Research Foundation (CPF2015-4).

\section{Author contributions}

Experiments were conceived and designed by Z.J.Z and G.N.P. R.T, Y.N.T, S.Z.C and L.H.S collected samples. Experiments were performed by Z.J.Z, J.M.D, Y.W, X.B.G and J.L.D, and the data were analyzed by Z.J.Z, S.M.Y, H.F.L and Y.G. The manuscript was written by Z.J.Z, J.M.D and G.W.Y. All authors read and approved the final manuscript.

Acknowledgements. The authors thank Guangwen Yan for giving advice on sample collection. We sincerely thank Robin B Gasser 
and Tao Wang from the University of Melbourne, Australia for technical support and comments on the draft manuscript.

\section{Supplementary Material}

Table S1 is available at https://www.parasite-journal.org/ 10.1051/parasite/2018023/olm

\section{References}

1. Caccio SM, Beck R, Lalle M, Marinculic A, Pozio E. 2008. Multilocus genotyping of Giardia duodenalis reveals striking differences between assemblages A and B. International Jounal for Parasitology, 38(13), 1523-1531.

2. Eckmann L. 2003. Mucosal defences against Giardia. Parasite Immunology, 25(5), 259-270.

3. Fayer R. 2004. Cryptosporidium: a water-borne zoonotic parasite. Veterinary Parasitology, 126(1-2), 37-56.

4. Feng Y, Xiao L. 2011. Zoonotic potential and molecular epidemiology of Giardia species and giardiasis. Clinical Microbiology Reviews, 24(1), 110-140.

5. Gong C, Cao XF, Deng L, Li W, Huang XM, Lan JC, Xiao QC, Zhong ZJ, Feng F, Zhang Y, Wang WB, Guo P, Wu KJ, Peng GN. 2017. Epidemiology of Cryptosporidium infection in cattle in China: a review. Parasite, 24, 1 .

6. Hingole AC, Gudewar JG, Pednekar RP, Gatne ML. 2017. Prevalence and molecular characterization of Cryptosporidium species in cattle and buffalo calves in Mumbai region of India. Journal of Parasitic Diseases, 41(1), 131-136.

7. Hu S, Liu Z, Yan F, Zhang Z, Zhang G, Zhang L, Jian F, Zhang S, Ning C, Wang R. 2017. Zoonotic and host-adapted genotypes of Cryptosporidium spp., Giardia duodenalis and Enterocytozoon bieneusi in dairy cattle in Hebei and Tianjin, China. Veterinary Parasitology, 248, 68-73.

8. Huang J, Yue D, Qi M, Wang R, Zhao J, Li J, Shi K, Wang M, Zhang L. 2014. Prevalence and molecular characterization of Cryptosporidium spp. and Giardia duodenalis in dairy cattle in Ningxia, northwestern China. BMC Veterinary Research, 10, 292.

9. Hunter PR, Nichols G. 2002. Epidemiology and clinical features of Cryptosporidium infection in immunocompromised patients. Clinical Microbiology Reviews, 15(1), 145-154.

10. Li F, Wang H, Zhang Z, Li J, Wang C, Zhao J, Hu S, Wang R, Zhang L, Wang M. 2016. Prevalence and molecular characterization of Cryptosporidium spp. and Giardia duodenalis in dairy cattle in Beijing, China. Veterinary Parasitology, 219, 61-65.

11. Li J, Qi M, Chang Y, Wang R, Li T, Dong H, Zhang L. 2015. Molecular characterization of Cryptosporidium spp., Giardia duodenalis, and Enterocytozoon bieneusi in captive wildlife at Zhengzhou zoo, China. Journal of Eukaryotic Microbiology, 62(6), 833-839.

12. Li J, Wang H, Wang R, Zhang L. 2017. Giardia duodenalisinfections in humans and other animals in China. Frontiers in Microbiology, 8, 2004.

13. Liu G, Su Y, Zhou M, Zhao J, Zhang T, Ahmad W, Lu H, Jiang N, Chen Q, Xiang M, Yin J. 2015. Prevalence and molecular characterization of Giardia duodenalis isolates from dairy cattle in northeast China. Experimental Parasitology, 154(3), 20-24.

14. Matsuura Y, Matsubayashi M, Nukata S, Shibahara T, Ayukawa O, Kondo Y, Matsuo T, Uni S, Furuya M, Tani H, Tsuji N, Sasai K. 2017. Report of fatal mixed infection with Cryptosporidium parvum and Giardia intestinalis in neonatal calves. Acta Parasitologica, 62(1), 214-220.
15. Nolan MJ, Jex AR, Mansell PD, Browning GF, Gasser RB. 2009. Genetic characterization of Cryptosporidium parvum from calves by mutation scanning and targeted sequencing zoonotic implications. Electrophoresis, 30(15), 2640-2647.

16. Petri WA Jr, Miller M, Binder HJ, Levine MM, Dillingham R, Guerrant RL. 2008. Enteric infections, diarrhea, and their impact on function and development. Journal of Clinical Investigation, 118(4), 1277-1290.

17. Qi M, Wang H, Jing B, Wang D, Wang R, Zhang L. 2015. Occurrence and molecular identification of Cryptosporidium spp. in dairy calves in Xinjiang, Northwestern China. Veterinary Parasitology, 212(3-4), 404-407.

18. Qi M, Wang H, Jing B, Wang R, Jian F, Ning C, Zhang L. 2016. Prevalence and multilocus genotyping of Giardia duodenalis in dairy calves in Xinjiang, Northwestern China. Parasites \& Vectors, 9, 546.

19. Ryan U, Caccio SM. 2013. Zoonotic potential of Giardia. International Journal for Parasitology, 43, 943-956.

20. Ryan U, Fayer R, Xiao L. 2014. Cryptosporidium species in humans and animals: current understanding and research needs. Parasitology, 141(13), 1667-1685.

21. Ryan U, Zahedi A, Paparini A. 2016. Cryptosporidium in humans and animals - a one health approach to prophylaxis. Parasite Immunology, 38(9), 535-547.

22. Santin M, Dargatz D, Fayer R. 2012. Prevalence of Giardia duodenalis assemblages in weaned cattle on cow-calf operations in the United States. Veterinary Parasitology, 183(3-4), 231-236.

23. Sulaiman IM, Hira PR, Zhou L, Al-Ali FM, Al-Shelahi FA, Shweiki HM, Iqbal J, Khalid N, Xiao L. 2005. Unique endemicity of cryptosporidiosis in children in Kuwait. Journal of Clinical Microbiology, 43(6), 2805-2809.

24. Taha S, Elmalik K, Bangoura B, Lendner M, Mossaad E, Daugschies A. 2017. Molecular characterization of bovine Cryptosporidium isolated from diarrheic calves in the Sudan. Parasitology Research, 116(11), 2971-2979.

25. Tao W, Li Y, Yang H, Song M, Lu Y, Li W. 2018. Widespread occurrence of zoonotic Cryptosporidium species and subtypes in dairy cattle from northeast China: public health concerns. Journal of Parasitology, 104(1), 10-17.

26. Wang H, Zhao G, Chen G, Jian F, Zhang S, Feng C, Wang R, Zhu J, Dong H, Hua J, Wang M, Zhang L. 2014. Multilocus genotyping of Giardia duodenalis in dairy cattle in Henan, China. PLoS One, 9(6), e100453.

27. Wang R, Wang H, Sun Y, Zhang L, Jian F, Qi M, Ning C, Xiao L. 2011. Characteristics of Cryptosporidium transmission in preweaned dairy cattle in Henan, China. Journal of Clinical Microbiology, 49(3), 1077-1082.

28. Wang R, Zhao G, Gong Y, Zhang L. 2017. Advances and perspectives on the epidemiology of bovine Cryptosporidium in China in the past 30 years. Frontiers in Microbiology, 8 , 1823.

29. Wang X, Cai M, Jiang W, Wang Y, Jin Y, Li N, Guo Y, Feng Y, Xiao L. 2017. High genetic diversity of Giardia duodenalis assemblage E in pre-weaned dairy calves in Shanghai, China, revealed by multilocus genotyping. Parasitology Research, 116(8), 2101-2110.

30. Wang X, Wang R, Ren G, Yu Z, Zhang L, Zhang S, Lu H, Peng X, Zhao G. 2016. Multilocus genotyping of Giardia duodenalis and Enterocytozoon bieneusi in dairy and native beef (Qinchuan) calves in Shaanxi province, northwestern China. Parasitology Research, 115(3), 1355-1361.

31. Xiao L, Feng Y. 2008. Zoonotic cryptosporidiosis. Fems Immunology \& Medical Microbiology, 52(3), 309-323. 
32. Zhang W, Wang R, Yang F, Zhang L, Cao J, Zhang X, Ling H, Liu A, Shen Y. 2013. Distribution and genetic characterizations of Cryptosporidium spp. in pre-weaned dairy calves in northeastern China's Heilongjiang province. PLoS One, 8(1), e54857.

Cite this article as: Zhong Z, Dan J, Yan G, Tu R, Tian Y, Cao S, Shen L, Deng J, Yu S, Geng Y, Gu X, Wang Y, Liu H \& Peng G. 2018. Occurrence and genotyping of Giardia duodenalis and Cryptosporidium in pre-weaned dairy calves in central Sichuan province, China. Parasite 25, 45.

\section{-0 PARASTE}

An international open-access, peer-reviewed, online journal publishing high quality papers on all aspects of human and animal parasitology

Reviews, articles and short notes may be submitted. Fields include, but are not limited to: general, medical and veterinary parasitology; morphology, including ultrastructure; parasite systematics, including entomology, acarology, helminthology and protistology, and molecular analyses; molecular biology and biochemistry; immunology of parasitic diseases; host-parasite relationships; ecology and life history of parasites; epidemiology; therapeutics; new diagnostic tools.

All papers in Parasite are published in English. Manuscripts should have a broad interest and must not have been published or submitted elsewhere. No limit is imposed on the length of manuscripts.

Parasite (open-access) continues Parasite (print and online editions, 1994-2012) and Annales de Parasitologie Humaine et Comparée (1923-1993) and is the official journal of the Société Française de Parasitologie. 